\title{
Food Allergies in Respiratory Sensitization
}

\author{
Vladimir Klimov ${ }^{1}$ and Andrew Klimov ${ }^{1}$ \\ ${ }^{1}$ Affiliation not available
}

August 24, 2021

Keywords: food allergens; sensitization routes; allergic rhinitis; asthma; food allergy

The full names of authors :

(1) Vladimir V. KLIMOV ${ }^{1}, \mathrm{PhD}, \mathrm{ScD}, \mathrm{MD}$, Prof., e-mail: klimov@mail.tomsknet.ru;

ORCID iD 0000-0001-6673-7556;

(2) Andrew V. KLIMOV ${ }^{1,2}$, PhD, MD, Assoc. Prof., e-mail: klimov.lor@mail.ru;

ORCID iD 0000-0002-2776-5834.

The author's institutional affiliations :

${ }^{1}$ Immunology \& Allergy Department, Siberian State Medical University, 2 Moscowsky tr, Tomsk, 634050, Russia;

${ }^{2}$ ENT Department, Siberian State Medical University, 2 Moscowsky tr, Tomsk, 634050, Russia.

Author for correspondence: Vladimir V. KLIMOV, postal address: 28 Vershinin Str, Ap. 5, Tomsk, 634041, Russia; e-mail: klimov@mail.tomsknet.ru

\begin{abstract}
The review is focusing on the uncommon route of food sensitization through the unified airway. Food allergies represent a real challenge in the face of modern civilization, taking into account a high prevalence and increased morbidity rates of this pathology. Current literature sources exhibit the problem of airwayrelated food allergies is underestimated. We describe immune responses to food allergens, which proceed in the respiratory tract, and the fate of shaped memory T cells and B cells. Many questions of food allergies in the total and airway-related mechanism of the pathology, in particular, remain poorly understood. Hopefully, future research will elucidate the problem that is at the cutting-edge.
\end{abstract}

Keyword s: food allergens; sensitization routes; allergic rhinitis; asthma; food allergy

\section{Abbreviations}

Th2 type 2 helper T cells

TSLP thymic stromal lymphopoietin

mDC-1 type 1 myeloid (conventional) dendritic cell

Tfh follicular helper $\mathrm{T}$ cell

ILC2 group 2 innate lymphoid cell 
TLR toll-like receptor

PRR pattern recognition receptor

PAMP pathgen-associated molecular pattern

DAMP damage-associated molecular pattern

APC allergen-presenting cell

HLA human major histocompatibility complex

FceRI type 1 Fc-receptor for IgE

\section{Introduction}

Food allergy is a pathologic process associated with food eating when the immune system responds to nutrients as allergens and develops allergic inflammation in the gut, unified airway, skin, and even genitourinary tract. Food allergies may develop in different phenotypes such as Th2-high (IgE-dependent), Th2-low, IgEindependent, and immune system-independent phenotypes. Atopic sensitization due to IgE overproduction is prevalent. Food allergy and food intolerance are two distinct conditions but are commonly confused because they occasionally share similar symptoms. In developed countries, self-reported prevalence of food allergies makes up $3 \%$ through $7,5 \%$ in adults $[1 ; 2]$, whereas food intolerance affects more than half the world's population not causing severe reactions. Systemic food anaphylaxis is a severe life-threatening form of food allergies, which occurs in selected atopic individuals and has no reliable predictive biomarkers [3: 4]. For example, in Ontario, Canada, morbidity from food anaphylaxis in 1999-2011 was 12 cases [1].

\section{Allergenicity of food allergens and routes of sensitization to them}

There are four routes of IgE-dependent sensitization to food allergens: (1) gastrointestinal; (2) respiratory; (3) transcutaneous [5; 6: 7], and (4) rare genitourinary [8]. Accordingly, clinical manifestations are localized in the same target organs, including cardiovascular and central nervous systems, if anaphylaxis occurs $[3: 7 ; 9 ; 10]$. Not all food proteins are allergens, therefore subject to allergenicity of food allergens is very important. Allergenicity is the allergen's ability to induce a non-adequate adaptive immune response, characterized by the overactivation of the immune system, absence of protective effect, and development of allergic inflammation and possible own tissue damage instead. Allergenicity is evaluated by many methods such as bioinformatics analysis, serological assays, mass spectrometry, cell experiments, animal models, etc. [11; 12; 13]. There are some families and three classes of food allergens [14]. Class 1 food allergens (cow's milk, peanut, hen's egg, etc.) are oral allergens that cause sensitization via the gastrointestinal tract and display severe clinical symptoms. Class 2 food allergens (e.g., birch) are aeroallergens that evoke sensitization via the respiratory tract and exert not severe cross-reactions termed "oral allergy syndrome," or "pollen food allergy syndrome" $[15 ; 16]$. Class 3 food allergens (e.g., small food proteins, additives, and contaminants) not having the capacity of cross-reactivity, which sensitize via the unified airway or skin and frequently cause occupational allergies [14].

Food protein allergenicity depends on many factors: antigenic structure (multiple epitopes capable of linear IgE binding), molecular weight lower than $70 \mathrm{kDa}$, stability, solubility in water, interaction with lipids, abundance in food, biochemical characteristics of proteins allowing to pass the extremes of food processing and proteolysis by digestive enzymes, combination with adjuvants in food, ability to promote the production of high levels of allergen-specific IgE and high-affinity allergen-specific IgE, pathologic imbalance in the target organ's microbiota, damaged mucosal barriers, decreased enzyme secretion, deficiency in sIgA, atopic predisposition of a person, etc. [17; 18].

"The Big Eight" food allergens cause about $90 \%$ of all food-allergic reactions. They are cow's milk, hen's eggs, peanuts, tree nuts, wheat, fish, and crustacean shellfish. Food allergies to cow's milk, egg, and wheat often are outgrown as grown-up children acquire allergen tolerance, whereas allergies to peanuts, tree nuts, 
fish, and shellfish commonly persists over a lifetime exhibiting the high association with anaphylaxis $[1 ; 16$; 19].

\section{Sensitization to a food allergen through the unified airway}

The first or new sensitization to food allergens may happen if they come by inhalation promoting food allergies, asthma, allergic rhinitis, atopic dermatitis, and systemic anaphylaxis development. Food allergic reactions by inhalation often occur in individuals already sensitized to the food, generally by ingestion. The recurrence, however, can appear due to de novo sensitization through inhalation. The dual-allergen exposure hypothesis postulates that early oral exposure to food allergens induces tolerance, whereas exposure at non-gastrointestinal sites, such as the skin or respiratory tract, results in food sensitization and allergy development $[20 ; 21 ; 22]$. The gut has a potent tolerogenic network, which consist of pro-tolerogenic cells and molecules due to the specific autonomous enteric nevrous system and mucosal immune system [23; 24]. The gut is a zone of allergen tolerance. On the whole, food allergy is often a series of allergic episodes, does not look like a typical atopic disease, and represents a known exception to the rule conceived by evolution.

More commonly reported inhaled food allergens are wheat flour, seafood (preferentially, crustaceans), soy, peanut, hen's egg, and milk [25]. The exposure to food allergens may proceed at home, in schools, restaurants, grocery stores, commercial flights, and occupational environments. Inhalation of food allergen depends on its airborne presence. Food processing, such as boiling, steaming, or frying, can release significant quantities of food allergens and promote the inhalation route of sensitization [25]. However, the respiratory route appears not to be isolated and is combined with gastrointestinal and transcutaneous sensitization to food allergens, though the airway route in food allergies is still underestimated.

On the one hand, many food allergens are found in household dust [26; 27], and many food allergens causing occupational allergies act as primary sensitizers through inhalation, with no evidence of cross-reactivity to other common inhalant allergen sources [14]. On the other hand, food sources contain food products (cereals, plants/vegetables/fruits/spices, seeds, herbal teas, mushrooms, seafood, and farm products), additives (colorants, thickening agents, sulfites, and enzymes), and food contaminants (mites, insects, fungi, and parasites) $[28 ; 29]$. These agents commonly represent proteins $(>10 \mathrm{kDa})$ derived from food sources, which may operate as respiratory sensitizers through the unified airway [14].

Food allergens penetrate the body via the unified airway route, get into the nasal and lung submucosae, where the immune system responds to these allergens. Researchers demonstrated the peanut allergens triggered IL33 and thymic stromal lymphopoietin (TSLP) synthesis in primary human nasal or bronchial epitheliocytes and stimulated maturation and migration of peanut-specific nasal/lung mDC-1 cells to draining lymph nodes. In addition, inhalational exposure to peanut and indoor dust induced peanut-specific Th2 cell differentiation and accumulation of Tfh cells in draining lymph nodes, which were associated with increased B cells numbers and peanut-specific IgE and IgG1 production [20].

In response to a food allergen (see Fig. 1), epitheliocytes produce alarmins (danger signal), IL-25, IL-33, and TSLP, which upregulate group 2 innate lymphoid (ILC2) cells, dendritic (DCs) cells, and type 2 helper T (Th2) cells. Pro-immunogenic neuropeptide neuromedin U promotes ILC2 cells [30; 31; 32]. Conversely, endogenous neuropeptide calcitonin-gene-related peptide (CGRP) is a critical negative regulator of ILC2 responses in vivo [33; 34]. The alarmins are essential stimulators of type 2 immunity, as they lead to the production of IL-5, IL-9, and IL-13, but they can participate in the IgE-independent pathway of allergic inflammation [32; 35]. Toll-like receptors (TLRs) related to pattern recognition receptors (PRRs) bind to pathogen-associated molecular (PAMP) patterns or damage-associated molecular (DAMP) patterns, and after signaling, promote the release of alarmins, synthesis of cytokines, and development of pyroptosis, creating the link between adaptive and innate immunity. 


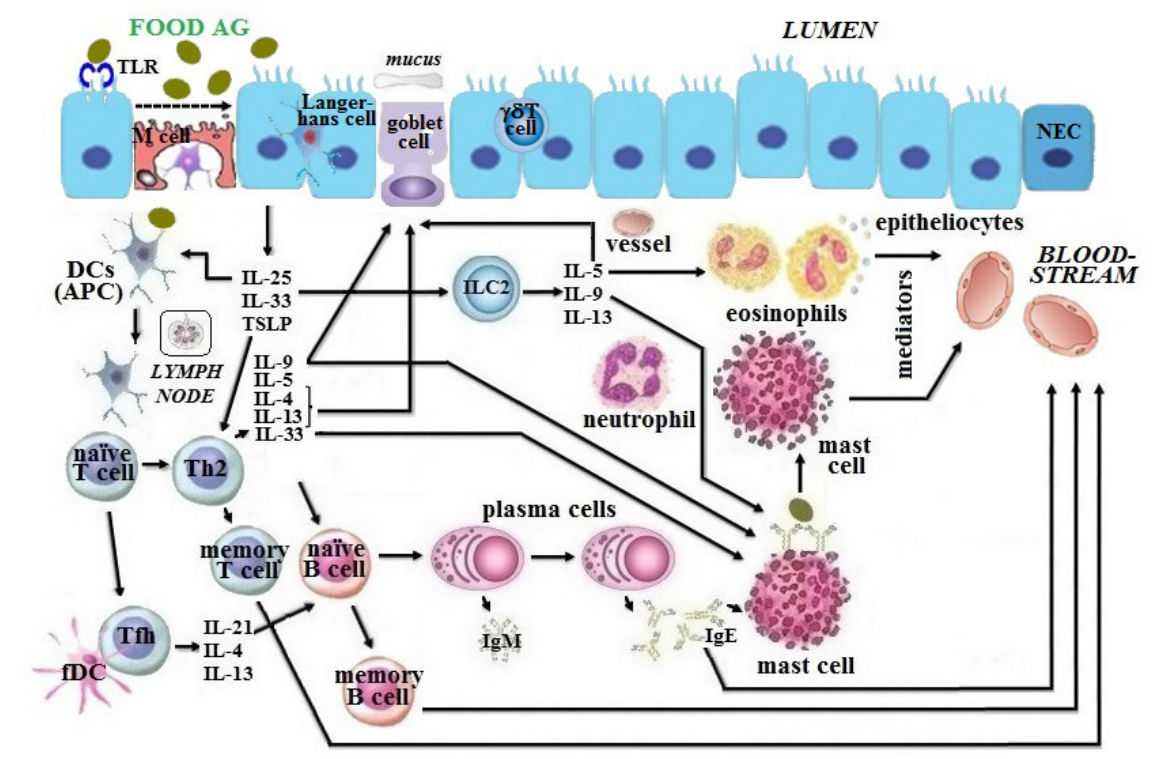

Fig.1. Sensitization to a food allergen through the unified airway

See description in the text. AG - allergens, DCs - dendritic cells, APC - allergen-presenting cells, Th2 type 2 helper T cells, Tfh - follicular helper T cells, fDC - follicular dendritic cells, ILC2 - group 2 innate lymphoid cells, NEC - neuroendocrine cells, TLR - toll-like receptors

A food allergen that passes the epithelial barriers is processed by dendritic cells (DCs), i.e., allergenpresenting (APC) cells, which in turn migrate to draining lymph nodes, where they present allergen-derived peptides on HLA class II molecules to naïve T cells. The naïve T cells differentiate into Th2 cells and follicular helper T (Tfh) cells. Th2 cells produce type 2 cytokines such as IL-4, IL-5, IL-9, IL-13, IL-33 and drive allergic response $[36 ; 37 ; 38 ; 39]$. Tfh cells secrete IL-21, IL-4, IL-13, which promote IgE class switch recombination in $\mathrm{B}$ cells, plasma cell maturation, and allergen-specific IgE production. The IgE antibodies may contribute to the allergic inflammation in the unified airway, e.g., in allergic rhinitis or asthma. In this case, the allergen-specific IgE antibodies bind to FceRI molecules on mast cells and basophils, resulting in their degranulation and allergic inflammation development due to histamine and other mediators of innate effector cells. Simultaneously, shaping two types of allergen-specific memory cells, (1) memory T cells and (2) memory B cells, occurs. These memory cells and IgE antibodies get into the bloodstream and then into the gastrointestinal tract.

Oral tolerance, an antipode of food allergies and a form of allergen tolerance, is a physiologic process of nutrient absorption with no adverse reaction. However, oral tolerance depends on multiple factors, which can maintain or destabilize it under the everyday entry of food proteins, dynamic gut microbiota, changing signals from neuro molecules, and continuous trafficking of pro-inflammatory cells and molecules [40]. Furthermore, it is unknown if feeding allergens can also induce true immune tolerance after generating a memory immune response [41].

\section{Co-influence of respiratory and food allergies}

Different forms of allergies affect approximately one-third of the world's population in Europe, and the rates are growing. There is a tendency for several allergic diseases to be present in the same individual simultaneously [42]. In the epidemiological study, allergic rhinitis occurred in $46.4 \%$, asthma was in $11.2 \%$, and allergic multimorbidity was diagnosed in $9.7 \%$ compared with a single allergic disease in $43.4 \%$. The current study's findings indicated an association between food allergies and the presence of at least one allergic disease [43]. 
However, isolated allergic rhinitis and asthma are not inherent in food allergic reactions, but respiratory symptoms may be part of anaphylaxis. Most asthmatic reactions to inhaled food allergens are described in occupational settings [44]. In the workplaces, 372 different potential causative allergens were identified, including seafood, wheat flour, and hen's eggs that might lead to asthma. Workers exposed to inhaled egg allergens developed rhinitis and asthma first and subsequently other allergic symptoms to the ingested egg. Subjects who inhaled wheat flour developed asthma with or without wheat ingestion [44].

Food allergy is frequently underestimated in association with asthma, but food allergy has been shown to trigger or exacerbate bronchial obstruction in asthma. There were reported that $34-78 \%$ of 82 asthmatic patients in Taiwan had food-related symptoms. Foods most commonly linked with their complaints were crab (67.9\%), cow's milk (53.6\%), shrimp (50\%), and other food allergens [45]. 1722 children between 0 and 14 years old in Sichuan province, China, were enrolled in this study. 59.7\% of children were allergic to at least one allergen, comprising $24.9 \%$ to aeroallergen and $38.8 \%$ to a food allergen, respectively, whereas $36.28 \%$ of children were allergic to both aeroallergen and food allergen. Also, there have been revealed that milk, egg, and house dust mites were the most common allergens. However, an analysis of the pattern of food allergen and aeroallergen sensitization was invaluable to the effective diagnosis and treatment of allergic diseases [46].

In the study of 200 patients in Iraq in which skin prick testing was conducted, it has been found that $46 \%$ of allergic rhinitis cases were caused by foods, including cumin (88.98\%), tea (62.96\%), pepper (59.25\%), almond (51.85\%) and other food allergens [47]. 252 patients with asthma, allergic rhinitis, and combined pathology in north India participated in the study. The prevalence of food sensitization based on specific IgE to respective foods was $17 \%$ with cereals and legumes [48]. Among 258 patients in Mexico included in the study, the most common underlying condition was allergic rhinitis $(59 \%)$. The prevalence of food sensitization (preferably to soybeans) was $40 \%$ [49].

In the clinical study of a case of a 38-year-old mold-allergic patient, it has been demonstrated that prior sensitization to mold aeroallergens might explain severe food reactions to cross-reacting homologs mushroom proteins. In addition, there was a well-recognized relationship between sensitization to airborne molds and allergy to mushrooms ingestion [50]. In another clinical study of a series of six patient cases with immediate occupational allergy (allergic rhinitis, asthma, and urticaria) to buckwheat, it has been revealed that patients had anaphylaxis after ingestion of food that contained buckwheat [51].

So, food allergy and non-enteric atopic diseases often coexist, and they are interconnected beyond the presence of simple comorbidity [44].

\section{Conclusions}

Food allergy is a challenge inherent in our civilization that may develop in different phenotypes such as Th2-high (IgE-dependent), Th2-low, IgE-independent, and immune system-independent phenotypes and by distinct pathogenic mechanisms and routes of sensitization. The airway route is described $[14 ; 20 ; 25]$ but underestimated. Food allergens penetrate the body through the unified airway route, get into the nasal and lung submucosae, where the immune system responds to these allergens, and then established memory cells and IgE antibodies come via the bloodstream to the gastrointestinal tract [20]. According to the current literature sources, food allergy and non-enteric atopic diseases like allergic rhinitis and asthma often coexist in the context beyond the presence of simple comorbidity [44].

\section{References}

1. Waserman S, Beegin P, Watson W. IgE-mediated food allergy.Allergy Asthma Clin Immunol. 2018; 14 (2): 71-81. DOI: doi.org/10.1186/s13223-018-0284-3

2. Sicherer SH, Dampson HA. Food allergy: A review and update on epidemiology, pathogenesis, diagnosis, prevention, and management.J Allergy Clin Immunol. 2017; 141(1): 41-58. DOI: https://doi.org/10.1016/j.jaci.2017.11.003 
3. Beck SC, Wilding T, Buka RJ, Baretto RL, Huissoon AP, Krishna MT. Biomarkers in human anaphylaxis: A critical appraisal of current evidence and perspectives. Front Immunol. 2019; 10:494. DOI: 10.3389/fimmu.2019.00494

4. Reber LL, Hernandez JD, Galli SJ. The pathophysiology of anaphylaxis.J Allergy Clin Immunol. 2017; 140(2):335-348. DOI: https://doi.org/10.1016/j.jaci.2017.06.003.

5. Kelleher MM, Tran L, Boyle RJ. Prevention of food allergy - skin barrier interventions. Allergol Int. 2020; 69: 3-10. DOI: https://doi.org/10.1016/j.alit.2019.10.005

6. van Splunter M, Liu L, van Neerven RJJ, Wichers HJ, Hettinga KA, de Jong NW. Mechanisms underlying the skin-gut cross talk in the development of IgE-mediated food allergy. Nutrients . 2020; 12: 3830. DOI: $10.3390 /$ nu12123830

7. Wang Y-H. Developing food allergy: a potential immunologic pathway linking skin barrier to gut. F1000Research. 2016; 5:2660. DOI:: 10.12688/f1000research.9497.1

8. Allam J-P, Haidl G, Novak N. Semen allergy. Hautarzt.2015;66(12):919-923. [German]. DOI: $10.1007 / \mathrm{s} 00105-015-3710-1$

9. Tomar S, Hogan S. Recent advances in mechanisms of food allergy and anaphylaxis. F1000Research. 2020; 9:863. DOI: https://doi.org/10.12688/f1000research.25638.1

10. Skypala IJ. Food-induced anaphylaxis: Role of hidden allergens and cofactors. Front Immunol. 2019; 10: 673. DOI: $10.3389 /$ fimmu.2019.00673

11. Pali-Schöll I, Verhoeckz K, Mafra I, Bavaro S, Mills ENC, Monaci L. Allergenic and novel food proteins: State of the art and challenges in the allergenicity assessment. Trends Food Sci Technol. 2019; 84: 45-48. DOI: https://doi.org/10.1016/j.tifs.2018.03.007

12. Fu L, Cherayil BJ, Shi H, Wang Y, Zhu Y. Allergenicity evaluation of food proteins. In: Food Allergy. Singapore: Springer; 2019: p. 93-122. DOI: https://doi.org/10.1007/978-981-13-6928-5_5

13. Hayes M. Chapter 14. Allergenicity of food proteins. In: Hayes M., editor. Novel Proteins for Food, Pharmaceuticals and Agriculture: Sources, Applications and Advances. Chichester: Wiley; 2018: DOI: https://doi.org/10.1002/9781119385332.ch14

14. Jeebhat MF, Moscato G, Bang BE, Folleti I, Lipińska-Ojrzanowska, Lopata AL, Pala G, Quirce S, Rauf M, Sastre J, Swoboda I, Walusiak-Skorupa J, Siracusa A. Food processing and occupational respiratory allergy - An EAACI position paper. Allergy. 2019; 74:1852-1871. DOI: 10.1111/all.13807

15. Carlson G, Coop C. Pollen food allergy syndrome (PFAS): A review of current available literature. Ann Allergy Asthma Immunol. 2019; 123(4): 359-365. DOI: https://doi.org/10.1016/j.anai.2019.07.022.

16. Valenta R, Hochwallner H, Linhart B, Pahr S. Food allergies: The basics. Gastroenterol. 2015; 148 (6): 1120-1131. DOI: 10.1053/j.gastro.2015.02.006

17. De Angelis E, Bavaro SL, Pilolli R, Monaci L. Food and nutritional analysis. Allergenic ingredients. In: Worsfold P., Townshend A., editors. Encyclopedia of Analytical Science. Elsevier; 2019; p.349-373: DOI: https://doi.org/10.1016/B978-0-12-409547-2.13957-5

18. Verhoeckx KCM, Vissers YM, Baumert JL, Faludi R, Feys M, Flanagan S, Herouet-Guicheney C, Holzhauser T, Shimojo R, van der Bolt N, Wichers H, Kimber I. Food processing and allergenicity. Food Chem Toxicol. 2015; 80: 223-240. DOI: http://dx.doi.org/10.1016/j.fct.2015.03.005

19. Koenig JFE, Bruton K, Phelps A, Grydziuszko E, Jimenez-Saiz R, Jordana M. Memory generation and re-activation in food allergy.Immunotarg Ther. 2021; 10: 171-184. DOI: https://doi.org/10.2147/ITT.S284823

20. Smeekens JM, Immormino RM, Balogh PA, Randell SH, Kulis MD, Moran TP. Indoor dust acts as an adjuvant to promote sensitization to peanut through the airway. Clin Exp Allergy. 2019; 49: 1500-1511. DOI: $10.1111 /$ cea. 13486

21. Kulis MD, Smeekens JM, Immormino RM, Moran TP. The airway as a route of sensitization to peanut: An update to the dual allergen exposure hypothesis. J Allergy Clin Immunol. 2021; DOI: https://doi.org/10.1016/j.jaci.2021.05.035

22. Du Toit G, Sampson HA, Plaut M, Burks AW, Akdis CA, Lack G. Food allergy: Update on prevention and tolerance. J Allergy Clin Immunol. 2018; 141(1): 30-40. DOI: https://doi.org/10.1016/j.jaci.2017.11.010 
23. Mittal R, Debs LH, Patel AP, Nguyen D, Patel K, O'Connor, Grati M, Mittal J, Yan D, Eshraghi AA, Deo SK, Daunert S, Liu XZ. Neurotransmitters: The critical modulators regulating gut-brain axis. $J$ Cell Physiol. 2017; 232(9): 2359-2372. DOI: 10.1002/jcp.25518

24. de Oliveira GLV, Cardoso CRB, Taneja V, Fasano A. Editorial: Intestinal dysbiosis in inflammatory diseases. Front Immunol.2021; 12: 727485. DOI: 10.3389/fimmu.2021.727485

25. Ramirez DAJ, Bahna SL. Food hypersensitivity by inhalation. Clin Mol Allergy . 2009; 7(4): 1-6. DOI: $10.1186 / 1476-7961-7-4$

26. Hindley JP, Chapman MD, Bernmingham M, Alvares I. Quantifying exposure to food allergens from household dust. $J$ Allergy Clin Immunol . 2019; 143(Suppl 2): AB251. DOI: https://doi.org/10.1016/j.jaci.2018.12.767

27. Trendelenburg V, Tschirner S, Niggemann B, Beyer K. Hen's egg allergen in house and bed dust is significantly increased after hen's egg consumption - A pilot study. Allergy. 2018; 73(1): 261-264. DOI: https://doi.org/10.1111/all.13303

28. Jeebhay MF, Bang B. Occupational allergy and asthma associated with inhalant food allergens. In: Lopata A, ed. Food Allergy - Molecular and Clinical Practice. Boca Raton: CRC Press, Taylor and Francis Group, 2017, 8:176-202. DOI: https://doi.org/10.1201/9781315120126

29. James JM, Crespo JF. Allergic reactions to foods by inhalation.Curr Allergy Asthma Rep. 2007; 7 : 167-174. DOI: $10.1007 / \mathrm{s} 11882-007-0017-\mathrm{z}$

30. Zheng H, Zhang Y, Pan J, Liu N, Qin L, Liu M, Wang T. The role of type 2 innate lymphoid cells in allergic diseases. Front Immunol.2021; 12: 586078. DOI: https://doi.org/10.3389/fimmu.2021.586078

31. Wallrapp A, Riesenfeld SJ, Burkett PR, Abdulnour RE, Nyman J, Dionne D, Hofree M, Cuoco MS, Rodman C, Farouq D, Haas BJ, Tickle TL, Trombetta JJ, Baral P, Klose CSN, Mahlakoiv T, Artis D, Rozenblatt-Rosen O, Chiu IM, Levy BD, Kowalczyk MS, Regev A, Kuchroo VK. The neuropeptide NMU amplifies ILC2-driven allergic lung inflammation. Nature. 2017; 549: 351-356. DOI: 10.1038/nature24029

32. Pasha MA, Patel G, Hopp R, Yang Q. Role of innate lymphoid cells in allergic diseases. Allergy Asthma Proc. 2019; 40: 138-45. DOI: 10.2500/aap.2019.40.4217

33. Wallrapp A, Burkett PR, Riesenfeld SJ, Kim SJ, Christian E, Abdulnour RE, Thakore PI, Schnell A, Lambden C, Herbst R, Khan P, Tsujikawa K, Ramnik J, Xavier RJ, Chiu IM, Levy BD, Regev A, Kuchroo VK. Calcitonin gene-related peptide negatively regulates alarmin-driven type 2 Innate Lymphoid Cell responses. Immunity. 2019, 51:709-723 e706. DOI: 10.1016/j.immuni.2019.09.005

34. Nagashima H, Mahlakoiv T, Shih HY, Davis FP, Meylan F, Huang Y, Harrison OJ, Yao C, Mikami Y, Urban Jr JF, Caron KM, Belkaid Y, Kanno Y, Artis D, O'Shea JJ. Neuropeptide CGRP limits group 2 innate lymphoid cell responses and constrains type 2 inflammation.Immunity. 2019, 51: 682-695.e686. DOI: 10.1016/j.immuni.2019.06.009

35. Yamauchi K, Ogasawara M. The role of histamine in the pathophysiology of asthma and the clinical efficacy of antihistamines in asthma therapy. Int J Mol Sci. 2019; 20: 1733. DOI: 10.3390/ijms20071733.

36. Drazdauskaitè G, Layhadi JA, Shamji MH. Mechanisms of allergen immunotherapy in allergic rhinitis. Curr Allergy Asthma Rep.2021; 21: 2. DOI: https://doi.org/10.1007/s11882-020-00977-7

37. Schoos A-MM, Bullens D, Chawes BL, De Vlieger L, DunnGalvin A, Epstein MM, Johan Garssen J, Hilger C, Knipping K, Kuehn A, Mijakoski D, Munblit D, Nekliudov NA, Ozdemir C, Patient K, Peroni D, Stoleski S, Stylianou E, Tukalj M, Verhoeckx K, Zidarn M, van de Veen W. Immunological outcomes of allergen-specific immunotherapy in food allergy. Front Immunol. 2020; 11: 568598. DOI: https://doi.org/10.3389/fimmu.2020.568598

38. Eiwegger T, Hung L, San Diego KE, O'Mahony L, Upton J. Recent developments and highlights in food allergy. Allergy. 2019; 74(12): 2355-2367. DOI: https://doi.org/10.1111/all.14082

39. Sampath V, Nadeau KC. Newly identified T cell subsets in mechanistic studies of food immunotherapy. J Clin Invest. 2019; 129(4): 1431-1440. DOI: https://doi.org/10.1172/JCI124605

40. Olivera A, Laky K, Hogan SP, Frischmeyer-Guerreiro P. Editorial: Innate cells in the pathogenesis of food allergy. Front Immunol. 2021; 2: 709991. DOI: https://doi.org/10.3389/fimmu.2021.709991

41. Tordesillas L, Berin MC. Mechanisms of oral tolerance. Clinic Rev Allerg Immunol. 2018; 55: 107-117. 
DOI: https://doi.org/10.1007/s12016-018-8680-5

42. Klimov AV, Isaev PYu, Klimov VV, Sviridova VS. Endotypes of allergic rhinitis and asthma accompanying food allergy. Bull Sib Med. 2019; 18 (2): 287-289. DOI: https://doi.org: 10.20538/1682-03632019-2-287-289

43. Skoczylas D, Gujski M, Bojar I, Raciborski F. Importance of food allergy and food intolerance in allergic multimorbidity. Ann Agricult Environ Med. 2020; 27(3): 413-417. DOI: 10.26444/aaem/123107

44. Emons JAM, van Wijk GR. Food allergy and asthma: Is there a link?.Curr Treat Options Allergy. 2018; 5: 436-444. DOI: https://doi.org/10.1007/s40521-018-0185-1

45. Wan K-S, Wu W-F, Liu Y-C, Huang C-S, Wu C-S, Hung C-W, Chang Y-S. Effects of food allergens on asthma exacerbations in schoolchildren with atopic asthma. Food Agricult Immunol. 2016; 28(2): 310-314. DOI: https://doi.org/10.1080/09540105.2016.1270260

46. Liu T, Lai S-y, Li W-s, Jiang Y-m. Prevalence of food allergen and aeroallergen sensitization among children in Sichuan province.Medicine. 2020; 99 (27): e21055. DOI: 10.1097/MD.0000000000021055

47. Abdullah YJ, Neamah SR. Allergic rhinitis caused by foods and their correlation to certain food allergens. Eurasia J Biosci. 2020; 14: 6719-6724

48. Chandni M, Pooran CK, Pushpa D, Anand BS. An evaluation of immune-profile and IgE binding proteins in the sera of respiratory allergy patients of north India to commonly consumed foods. Glob J Otolaryngol. 2019; 20(1): 556027. DOI: 10.19080/GJO.2019.20.556027

49. Bedolla-Barajas M, Torres-Alvarez NE, Contreras-Gonzalez U, Hernandez-Colin D, Bedolla-Pulido TI, Robles-Figueroa M, Morales-Romero J. High prevalence of food sensitization among adults with allergic diseases who live in the Guadalajara metropolitan area. [Spanish]. Rev Alerg Mex. 2017; 64(1): 66-75. Access at: http://www.revistaalergia.mx

50. Gabriel MF, Gonzalez-Delgado P, Postigo I, Fernandez J, Soriano V, Cueva B, Martinez J. From respiratory sensitization to food allergy: Anaphylactic reaction after ingestion of mushrooms(Agaricus bisporus).Med Mycol Case Rep. 2015; 8: 14-16. DOI: http://dx.doi.org/10.1016/j.mmcr.2015.02.003.

51. Jungewelter S, Airaksinen L, Pesonen M. Occupational buckwheat allergy as a cause of allergic rhinitis, asthma, contact urticaria and anaphylaxis - An emerging problem in food-handling occupations? Am J Idustr Med. 2020; 63(11): 1947-1053. DOI: https://doi.org/10.1002/ajim.23185

Figure Legend:

Fig.1. Sensitization to a food allergen through the unified airway

See description in the text. AG - allergens, DCs - dendritic cells, APC - allergen-presenting cells, Th2 type 2 helper T cells, Tfh - follicular helper T cells, fDC - follicular dendritic cells, ILC2 - group 2 innate lymphoid cells, NEC - neuroendocrine cells, TLR - toll-like receptors 